BMJ Paediatrics Open

\section{Poisonings with ADHD medication in children under the age of 5 years in Australia: a retrospective study, 2004- 2019}

To cite: Arbaeen A, Wheate NJ, Cairns R. Poisonings with ADHD medication in children under the age of 5 years in Australia: a retrospective study, 20042019. BMJ Paediatrics Open 2022;6:e001325. doi:10.1136/ bmjpo-2021-001325

- Additional supplemental material is published online only. To view, please visit the journal online (http://dx.doi.org/ 10.1136/bmjpo-2021-001325).

Received 17 November 2021 Accepted 10 December 2021

Check for updates

(c) Author(s) (or their employer(s)) 2022. Re-use permitted under CC BY-NC. No commercial re-use. See rights and permissions. Published by BMJ.

${ }^{1}$ School of Pharmacy, Faculty of Medicine and Health, The University of Sydney, Sydney, New South Wales, Australia ${ }^{2}$ New South Wales Poisons Information Centre, The Children's Hospital at Westmead, Sydney, NSW, Australia

Correspondence to Dr Rose Cairns; rose.cairns@ sydney.edu.au

\section{ABSTRACT}

Objective To describe the temporal relationships in attention-deficit hyperactivity disorder (ADHD) medication poisoning exposures in children; describe patient demographics, medications involved, poisoning exposure reasons and disposition.

Design A population-based, retrospective cohort study of calls to Australia's largest Poisons Information Centre. Poisoning exposure counts and dispensing-adjusted rates were modelled with Poisson, quasi-Poisson and negative binomial regression where appropriate.

Setting Calls to the New South Wales Poisons Information Centre and dispensings on the Pharmaceutical Benefits Scheme.

Patients Children under the age of 5 years.

Results There were 1175 poisoning exposures to ADHD psychostimulants, 2004-2019; averaging 73 per year. Accidental poisonings accounted for $94 \%$ of cases. Methylphenidate was most frequently implicated (63\%). Thirty-four per cent of cases were referred to hospital and a further $21 \%$ of calls were made by hospital staff. Poisoning exposure counts for all ADHD psychostimulants increased by $2.7 \%(95 \% \mathrm{Cl}=0.42 \%$ to $4.9 \%)$ per year; however, this differed by agent. Methylphenidate poisoning exposures increased by $5.2 \%$ per year $(95 \% \mathrm{Cl}=4.3 \%$ to $6.1 \%$ ), lisdexamfetamine increased by $62 \%$ per year (95\% $\mathrm{Cl}=48 \%$ to $76 \%$ ), while dexamphetamine poisoning exposures decreased by $5.5 \%$ per year $(95 \% \mathrm{Cl}=-9.5 \%$ to $-1.4 \%)$. These trends are reflected in the number of dispensings; however, dispensings increased at a faster rate than exposures. When poisoning exposures were expressed as dispensing-adjusted rates, there was a $16 \%$ decrease $(95 \% \mathrm{Cl}=-20 \%$ to $-13 \%)$ per year.

Conclusions ADHD medication use has increased, associated with an increased number of paediatric poisoning exposures. However, poisoning exposures per dispensed prescription has decreased. The majority of cases required hospitalisation, indicating the need for further poisoning prevention strategies.

\section{INTRODUCTION}

Attention-deficit hyperactivity disorder (ADHD) is a common condition with an estimated worldwide prevalence of $5.29 \%$. $^{1}$ Many countries report growing use of ADHD medications in recent years, ${ }^{2}$ with a major
What is known about the subject?

Attention-deficit hyperactivity disorder (ADHD) diagnoses and ADHD medication use are increasing worldwide.

- Children are at risk of ADHD medication poisonings due to exploratory behaviours and dosing errors.

- An ADHD medication overdose can cause lifethreatening toxicity in young children.

\section{What this study adds?}

ADHD medication poisoning exposures in young Australian children ( $<5$ years of age) have been increasing by $2.7 \%$ per year from 2004 to 2019 .

- Over half of all poisoning exposure cases required hospitalisation.

- ADHD medication dispensings have increased at over the same period.

adverse outcome of this growing use being the potential for increasing poisoning exposures, including fatal overdoses. ${ }^{3}$

In the USA, it is estimated that prescriptions for ADHD medications are written for more than 2.7 million children per year. ${ }^{4}$ There were 156365 poisoning exposures reported to US poison control centres from 2000 to 2014 among children and adolescents who were less than 20 years of age, with the poisoning exposure rate increasing by around $70 \%$ over between 2000 and 2011. ${ }^{3}$ Of these, $58891(38 \%)$ were aged under 5 years. In 2019, US poison centres received 9026 calls regarding methylphenidate poisoning exposures (all age groups); 1390 of these calls were for children under 5 years of age. ${ }^{5}$

In 2016, the prevalence of ADHD in Australian children was estimated to be between $2.4 \%$ and $7.4 \%$, depending on the age group. ${ }^{6}$ In 2019, approximately 197000 children under 14 were diagnosed with ADHD. ${ }^{6}$ ADHD medication use is increasing in Australia, with 
subsidised dispensings increasing on average $9.9 \%$ per year from 2013 to $2017 .{ }^{7}$ Over $40 \%$ of ADHD medication dispensings were for children aged from 6 to 12 years. ${ }^{7}$

The increased use of ADHD medications can lead to higher rates of poisoning exposures and overdose in young children, ${ }^{89}$ including exploratory ingestions and dosing errors. These poisonings can occur with medications prescribed for that child, or someone else (eg, a sibling). ADHD medication poisonings are of particular concern because psychostimulants can have adverse effects such as agitation, tachycardia and hypertension at low doses. ${ }^{3}$

Previous research regarding ADHD medication in Australian children has focused on dispensing, ${ }^{10}{ }^{11}$ and intentional poisoning exposures in older children. ${ }^{12}$ In this study, our aim was to (i) determine temporal relationships in paediatric ADHD medication poisoning exposures in Australian children, (ii) calculate trends in poisoning exposures adjusted for the number of dispensed prescriptions and (iii) describe the demographics, circumstances and disposition of the poisoning exposures. We focused on young children (under 5 years of age) as this group is particularly vulnerable to psychostimulant poisoning and the use of psychostimulants is not recommended in this age group.

\section{METHODS}

Design

This was a retrospective study of poisoning exposures to psychostimulants used to treat ADHD in Australian children from 2004 to 2019. During the study period, relevant medications included methylphenidate, dexamphetamine and lisdexamfetamine (which became available in late 2013, subsidised by the federal government from 2015 onwards). We used data from the New South Wales Poisons Information Centre (NSWPIC). Australia has four Poisons Information Centres (PICs), with the NSWPIC responding to approximately $50 \%$ of the nation's 205000 annual poisoning calls. The majority $(65 \%)$ of calls are from New South Wales (NSW), with the remaining calls taken from all other Australian jurisdictions due to the on-call nature of the Australian PIC system. We restricted the study to children aged under 5 years, with the following subcategories (derived from the NSWPIC database classification): neonate (0-4 weeks), infant ( 4 weeks-12 months) and toddler (1-4 years). We focused on temporal relationships of the poisoning exposures, expressed both as raw counts, and corrected for the number of prescriptions dispensed.

\section{Data source: the NSWPIC database}

The NSWPIC database was searched from 2004 to 2019 for poisoning exposures to ADHD psychostimulants in children under 5 years of age. Calls were included if the patient's age category at the time of poisoning was coded as neonate, infant or toddler. Re-calls (subsequent calls about a single exposure event) were excluded from the exposure count. Missing data were recorded as 'unknown'. The data collected for this study included year of the exposure, patient age and sex, medication, reason for the exposure, route of the exposure, management site/disposition, location (postcode or hospital name) and if applicable, the type of therapeutic error.

\section{Data source: pharmaceutical benefits scheme dispensings}

ADHD medication dispensing data were used to adjust for medication utilisation. Australia has a publicly funded healthcare system, with subsidised medicines available to citizens and permanent residents under the Repatriation Pharmaceutical Benefits Scheme and the Pharmaceutical Benefits Scheme (hereafter referred to as R/ PBS). We used publicly available data on dispensed medicines provided by the Australian government, available from (http://medicarestatistics.humanservices.gov.au/ statistics/mbs_item.jsp). This data provides populationlevel data on all dispensings that were subsidised by the government. Data are not provided by age group.

We extracted dispensing data for methylphenidate, dexamphetamine and lisdexamfetamine from 1 January 2004 to 31 December 2019. Prior to 2012, the R/PBS data only captured dispensing where the government paid a contribution (co-payment threshold). For cheaper medications, some beneficiaries paid the full cost of the medicine (defined as 'under co-payment'), and extraction of data related to these dispensed products was not able to be captured prior to 2012. ${ }^{13} 14$ For more information on PBS data capture changes see Mellish $e t$ al. ${ }^{13}$ For our main analysis (2004-2019), we included concessional beneficiaries only, to allow comparison of long-term trends. All dispensings (including under co-payment) were extracted for July 2012-December 2019 to confirm trends across the broader population group. Complete data (2004-2019) were available for dexamphetamine; methylphenidate data was used from 2005 (14 years of data); and for lisdexamfetamine, this medication was only R/PBS listed part way through 2015 (four full years of data). ${ }^{13}$

\section{Data analysis}

Poisoning exposure temporal relationships were analysed using the R program (V.4.0.3) ${ }^{15}$ Count data were analysed using Poisson regression or negative binomial regression with a log link function (when data were overdispersed). To analyse dispensing adjusted rates (poisoning exposures per prescriptions dispensed) quasi-Poisson regression was used.

Geographical distribution of paediatric ADHD medication poisoning exposures was examined by focusing on NSW, the Australian Capital Territory (ACT) and Tasmania (as NSWPIC takes calls from these jurisdictions on a near full-time basis). Postcodes were used for calls from the community, and the hospitals' locations were used to determine postcodes for hospitalised patients. The Accessibility/Remoteness Index of Australia (ARIA) was used to convert postcodes to scores by using the 


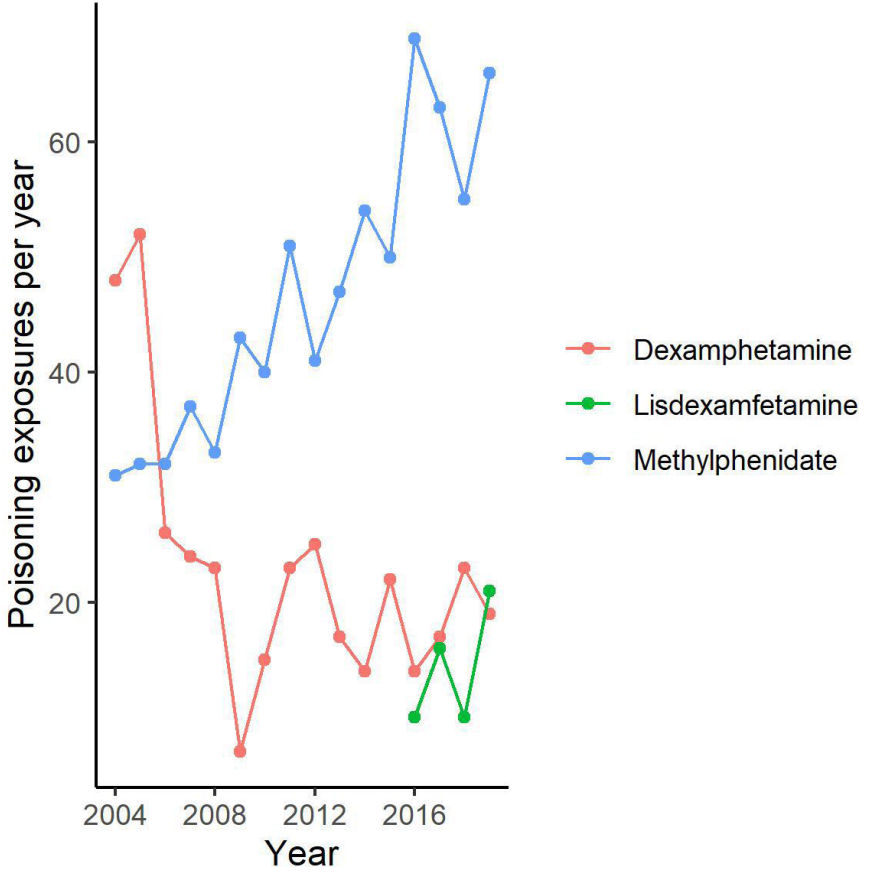

Figure 1 Annual number of paediatric (less than 5 years of age) poisoning exposures to attention-deficit hyperactivity disorder medication as reported to the New South Wales Poisons Information Centre from 2004 to 2019, broken down by agent.

psycho-oncology cooperative research group ARIA lookup tool to describe geographical disadvantage, ${ }^{16}$ and we compared this to overall population data from the Australian Bureau of Statistics.

\section{Patient and public involvement}

This was a retrospective review of routinely collected poisons centre and dispensing data. Patients and the public were not involved in the design or the recruitment of the study.

\section{RESULTS}

Over the 16-year study period there were 1470 calls (including re-calls regarding the same exposure) to the NSWPIC that met our inclusion criteria; of these, 1175 were unique poisoning exposure calls. The number of calls decreased from 2004 to 2009 and then increased from 2010 to 2019. There were on average 73 calls per year, with the number of calls increasing on average by $2.7 \%$ per year $(95 \% \mathrm{CI}=0.42 \%$ to $4.9 \%$ ) (online supplemental figure 1). Methylphenidate poisoning exposures increased by $5.2 \%$ per year $(95 \% \mathrm{CI}=4.3 \%$ to $6.1 \%)$ in contrast to dexamphetamine poisoning exposures which decreased by $5.5 \%$ per year $(95 \% \mathrm{CI}=-9.5 \%$ to $-1.4 \%)$. Lisdexamfetamine poisoning exposures increased by $62 \%$ per year from 2015 onwards $(95 \% \mathrm{CI}=48 \%$ to $76 \%)$ (figure 1). Dispensings for these medicines followed a similar trend, with dexamphetamine dispensings decreasing each year, while methylphenidate and lisdexamfetamine dispensings increased each year (figure 2).

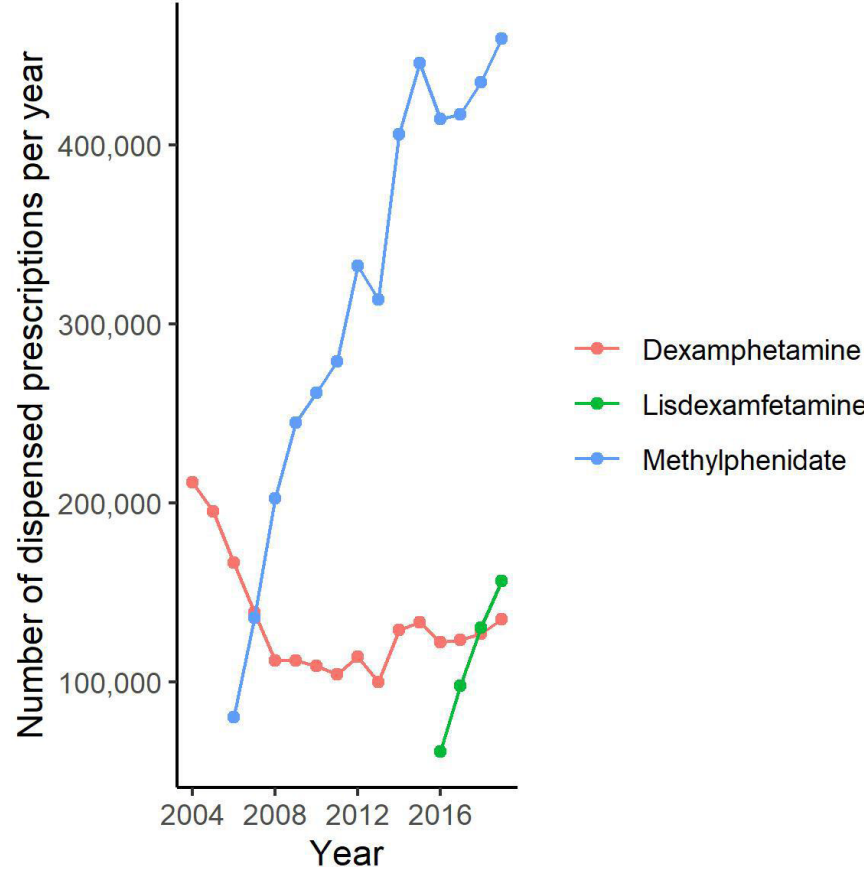

Figure 2 Pharmaceutical Benefits Scheme dispensings for attention-deficit hyperactivity disorder medications from 2004 to 2019.

The rate of poisoning exposures per concessional prescription dispensed decreased by $16 \%$ per year $(95 \%$ $\mathrm{CI}=-20 \%$ to $-13 \%$ ) (figure 3 ). There was a decrease in the rate of methylphenidate and dexamphetamine

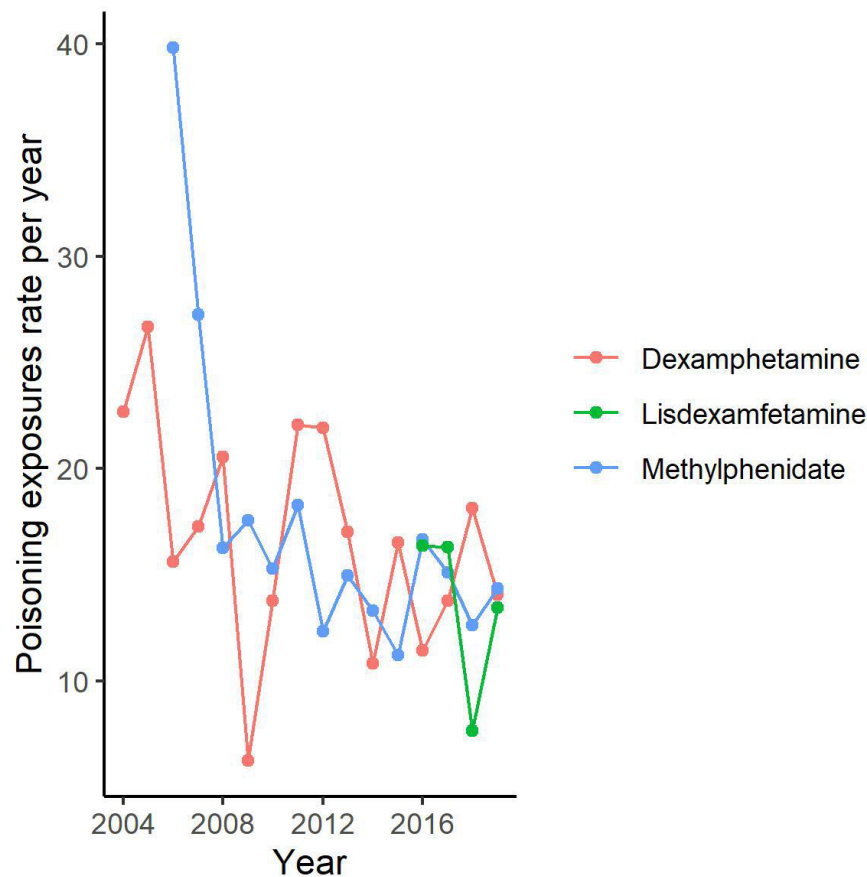

Figure 3 Annual number of paediatric (less than 5 years of age) poisoning exposures per Pharmaceutical Benefits Scheme script dispensed to each attention-deficit hyperactivity disorder medications as reported to the New South Wales Poisons Information Centre from 2004 to 2019. PBS dispensings were restricted to concessional beneficiaries only. 
poisoning exposures by $6.9 \%(95 \% \mathrm{CI}=-11 \%$ to $-2.4 \%)$ and $2.7 \%(95 \% \mathrm{CI}=-5 \%$ to $-0.5 \%)$ per year, respectively. The lisdexamfetamine poisoning exposure rate in paediatric populations reduced by $13 \%(95 \% \mathrm{CI}=-28.6 \%$ to $2.6 \%$ ) per year, from 2016 to 2019. From 2012 onwards, data capture allowed for examination of the trends for all patients (general and concessional beneficiaries). Dispensing adjusted exposure rates, when corrected for all patients, were broadly similar (online supplemental figure 2).

The characteristics of the cases are shown in table 1 . The median age was 2 years (IQR, 22-36 months). The distribution between the two sexes was approximately equal: male $(52 \%, 606)$, female $(44 \%, 522)$; sex was not recorded in the remaining cases. Toddlers (aged 1-4 years) accounted for most the poisoning exposures $(96 \%, 1133)$.

The most common reason for poisoning exposures was accidental ingestion due to exploratory behaviour $(94 \%$, 1104). Therapeutic errors by parents (including incorrect dose, incorrect time, incorrect patient and/or incorrect drug) occurred in 61 cases (5\%, table 1). Over half of the calls were received from family members $(61 \%, 893)$.

Fewer than half of the poisonings were managed at home $(40 \%, 465)$, with $34 \%$ (398) referred to hospitals by the NSWPIC. An additional 21\% (246) of patients were already in hospital at the time of the call to the NSWPIC.

The fields of the free-text case notes were examined to determine for whom the medication was prescribed. Who the medication was prescribed for was not recorded for over half of the cases $(63 \%, 737)$. Over a quarter of the poisoning exposures $(27 \%, 312)$ were to medications prescribed to the child's sibling. Only $4 \%$ (52) of patients were recorded to have been prescribed the medication (table 1).

Methylphenidate accounted for the majority of the poisoning exposures $(63 \%, 744)$, followed by dexamphetamine $(32 \%, 369)$ and lisdexamfetamine $(5 \%, 62)$ (online supplemental table 1).

Geographical analysis focused on NSW, the ACT and Tasmania, due to near-complete PIC call capture in these areas. Where geographical data were recorded, paediatric ADHD medication poisoning exposures were broken down by remoteness score and compared with the paediatric population in those areas. Analysis of the 545 calls with recorded geographical data showed that children in regional and remote areas appeared to be over-represented in these poisoning exposures (table 2).

\section{DISCUSSION}

Over the 16-year study period, Australian paediatric poisoning exposures to ADHD medications increased along with increased dispensings. However, when poisoning exposures were adjusted for the number of dispensed prescriptions, the rate was found to decrease. Trends varied by agent: methylphenidate and lisdexamfetamine poisoning exposures increased, while
Table 1 Characteristics of the 1175 attention-deficit hyperactivity disorder medication poisoning exposures in children under 5 years of age as reported to the NSWPIC, 2004-2019

\begin{tabular}{|c|c|}
\hline \multicolumn{2}{|l|}{ Sex } \\
\hline Male & $606(52 \%)$ \\
\hline Female & $522(44 \%)$ \\
\hline Unknown & $47(4 \%)$ \\
\hline \multicolumn{2}{|l|}{ Age } \\
\hline Median age (months) & 24 \\
\hline Quartiles 1 and 3 & $22-36$ \\
\hline \multicolumn{2}{|l|}{ Age category } \\
\hline Toddler (1-4 years) & $1133(96 \%)$ \\
\hline Infant (4 weeks-12 months) & $42(4 \%)$ \\
\hline \multicolumn{2}{|l|}{ Exposure type } \\
\hline Accidental & $1104(94 \%)$ \\
\hline Therapeutic error & $61(5 \%)$ \\
\hline Other & $5(<1 \%)$ \\
\hline Adverse reaction & $2(<1 \%)$ \\
\hline Intentional & $3(<1 \%)$ \\
\hline \multicolumn{2}{|l|}{ Caller background* } \\
\hline Family member & $893(61 \%)$ \\
\hline Doctor & $269(18 \%)$ \\
\hline Nurse & $241(16 \%)$ \\
\hline Ambulance & $36(2 \%)$ \\
\hline Other/unknown & $15(1 \%)$ \\
\hline Other medical professional & $9(1 \%)$ \\
\hline Friend & $7(<1 \%)$ \\
\hline Pharmacist & $2(<1 \%)$ \\
\hline \multicolumn{2}{|l|}{ Disposition } \\
\hline Stayed home & $465(40 \%)$ \\
\hline Referred to hospital & $398(34 \%)$ \\
\hline In hospital & $246(21 \%)$ \\
\hline Other & $48(4 \%)$ \\
\hline At GP surgery & $11(1 \%)$ \\
\hline Referred to GP & $7(<1 \%)$ \\
\hline \multicolumn{2}{|l|}{ Prescribed for } \\
\hline Not stated & $737(63 \%)$ \\
\hline Sibling & $312(27 \%)$ \\
\hline Other family member & $60(5 \%)$ \\
\hline Themselves & $52(4 \%)$ \\
\hline Friend & $14(1 \%)$ \\
\hline
\end{tabular}

${ }^{*}$ Caller background includes both the original call and subsequent re-calls about the same exposure. This information is collected to differentiate different people (parent, triage nurse, treating doctor) for the same child.

GP, general practitioner; NSWPIC, New South Wales Poisons Information Centre.

dexamphetamine poisoning exposures decreased. The average age at time of poisoning exposure was 2 years of age, with accidental exposures likely explained by exploratory behaviour. ${ }^{49}$ Where recorded, the medication was predominantly prescribed for a sibling. A large number of the poisonings were advised to visit their local hospital for assessment and possible treatment, and children in remote and regional areas appear to be at higher risk. 
Table 2 Attention-deficit hyperactivity disorder poisoning exposure calls originating from NSW, the ACT and Tasmania, 2004-2019, by their Accessibility/Remoteness Index of Australia (ARIA) 2016 score

\begin{tabular}{llcr}
\hline Location & $\begin{array}{l}\text { NSW/ACT/Tasmania child } \\
\text { population* }\end{array}$ & \multicolumn{1}{l}{$\begin{array}{l}\text { Poisonings with geographical } \\
\text { information† }\end{array}$} & \multicolumn{1}{c}{$\begin{array}{l}\text { Poisonings/100 000 } \\
\text { population/year }\end{array}$} \\
\hline Major cities & $382990(74 \%)$ & $246(45 \%)$ & 4.01 \\
Inner regional & $101518(20 \%)$ & $148(27 \%)$ & 9.11 \\
Outer regional & $32383(6 \%)$ & $138(25 \%)$ & 26.63 \\
Remote & $2544(<1 \%)$ & $9(2 \%)$ & 22.11 \\
Very remote & $556(<1 \%)$ & $4(<1 \%)$ & 44.96 \\
Multiple entriesł & - & 184 & - \\
\hline Total & 519991 & 545 & 6.55 \\
\hline
\end{tabular}

*Based on 2016 population estimates, children less than 5 years of age.

†Only poisoning exposures with geographical data recorded were included.

$\ddagger$ The postcode has more than one ARIA classification assigned to it.

ACT, Australian Capital Territory; NSW, New South Wales.

The number of paediatric ADHD medication poisoning exposures increased during the study period, driven mostly by calls about methylphenidate. While there was a marked increase in raw counts of methylphenidate poisoning exposures, once this was adjusted for the number of prescriptions dispensed, there was a noticeable decrease. This is because dispensed prescriptions increased at a faster rate than poisoning exposures. This finding was consistent with other PIC studies in which poisoning trends were correlated with the sale and the availability of medications. ${ }^{12}$ The trend in poisoning exposures appears to reflect overall medicine availability in the community.

There has been increased recognition of the dangers of ADHD medication in children, such as significant neurological and cardiovascular effects including agitation, tachycardia and hypertension. As such, in 2006 the Australian guidelines were changed to advise against use of ADHD medications in children under 6 years of age. ${ }^{17}$ Only a small percentage of patients in this study were prescribed the ADHD medication they were exposed to, indicating broad adherence to guidelines. The majority of poisoning exposures were accidental poisoning exposures to medicines prescribed to sibling or other family member. ADHD medication dispensing in older children (5-19 years) increased by $30 \%$ per year between 2013 and $2019,{ }^{10}$ consistent with our finding of increased use overall. The increase in ADHD medication use is consistent with previously described global, ${ }^{18} 19$ and Australian trends. ${ }^{711} 12$

In this study apparent geographical variability was identified, with rural and remote children being at increased risk when compared with metropolitan children. Children who lived in major cities in Australia were less likely to have high rates of ADHD medication poisoning exposures (4.01 poisoning exposures per 100000 population per year) compared with people who lived in inner regions (9.11 per 100000 ) or outer regions (26.63 per 100000 ), and remote and very remote areas (22.11 and 44.96 per 100000 , respectively). Other studies have consistently shown higher overall ADHD medication utilisation rates in rural and regional areas, particularly in areas with greater socioeconomic disadvantage,${ }^{2021}$ as defined by the Australian government. ${ }^{22}$ Therefore, the geographical disparity observed in this study is likely to be due to medication utilisation in these communities.

This study has a number of strengths and limitations. Strengths include having data from NSWPIC which is Australia's largest PIC, taking calls from members of the public and healthcare professionals. In addition, we were able to report on specific medications and details on poisonings exposure characteristics. This level of detail is not available in routinely coded hospitalisation data. The main limitations of this study are its retrospective design and the lack of complete outcome data. In addition, calls to the NSWPIC are voluntary, and thus, this study likely underestimates the true frequency of the ADHD medication poisonings. There may be bias in our geographical analysis, as certain people may be more or less likely to call PIC (eg, smaller/more remote hospitals may be more likely to call PIC for advice). In addition, the use of postcodes to code locations for child is based on normal practice where ordinarily a child will attend a hospital close to their home after a poisoning exposure, and thus the ARIA score will be the same. We acknowledge that this has limitations as it will underestimate the number of remote children (as they are more likely to travel to larger regions for hospital care). The geographical disadvantage may be even more pronounced than we have identified.

It is also important to note that the PBS data used in this study is at the population level, it includes the whole Australian population (all age groups) and not just those patients under 5 years of age. Therefore, when we adjusted for overall ADHD medication use, the calculation makes a broad assumption that trends in use in children are the same for adolescents and adults, which may not be accurate. Furthermore, our R/PBS analysis is limited by the lack of capture of private dispensed prescriptions. 


\section{CONCLUSIONS}

Overall, the total number of ADHD medication poisoning exposures increased in young Australian children, while dispensing of these medications also increased; the rate of dispensings increased more rapidly than the rate of increase in the poisoning exposures. Trends with individual agents differed, with methylphenidate and lisdexamfetamine use and poisoning exposures increasing over time, while dexamphetamine poisoning exposures decreased over the study period. Most poisonings were from exposure to someone else's medication, which is consistent with these medications not being recommended for patients in this age group. Many poisoning exposures resulted in hospitalisation, indicating the need for further poisoning prevention strategies in this area.

Twitter Abrar Arbaeen @aarb40, Nial J Wheate @NialWheate and Rose Cairns @ RoseFJCairns

Acknowledgements The authors thank the New South Wales Poisons Information Centre for access to the data. AA is a recipient of a Saudi Arabian Ministry of Education scholarship. RC is supported by a fellowship from the Australian National Health and Medical Research Council (NHMRC, grant ID: 1196516). The funding organisations played no part in the design of the study; nor in the preparation, review or approval of the manuscript.

Contributors AA collated and analysed the data, and prepared the manuscript. NJW helped with data analyses and helped to prepare the manuscript. RC devised and led the project, helped with data analysis and helped to draft the manuscript. $\mathrm{RC}$ acts as guarantor for this study.

Funding The authors have not declared a specific grant for this research from any funding agency in the public, commercial or not-for-profit sectors.

Competing interests None declared.

Patient consent for publication Not applicable.

Ethics approval This study was approved by the Sydney Children's Hospitals Network Human Research Ethics Committee (Approval number LNR/16/SCHN/44). This study is a retrospective study.

Provenance and peer review Not commissioned; internally peer reviewed.

Data availability statement Data may be obtained from a third party and are not publicly available. PBS data is freely available from the Medicare Statistics website. For privacy reasons, no further poisons centre data is available.

Supplemental material This content has been supplied by the author(s). It has not been vetted by BMJ Publishing Group Limited (BMJ) and may not have been peer-reviewed. Any opinions or recommendations discussed are solely those of the author(s) and are not endorsed by BMJ. BMJ disclaims all liability and responsibility arising from any reliance placed on the content. Where the content includes any translated material, BMJ does not warrant the accuracy and reliability of the translations (including but not limited to local regulations, clinical guidelines, terminology, drug names and drug dosages), and is not responsible for any error and/or omissions arising from translation and adaptation or otherwise.

Open access This is an open access article distributed in accordance with the Creative Commons Attribution Non Commercial (CC BY-NC 4.0) license, which permits others to distribute, remix, adapt, build upon this work non-commercially, and license their derivative works on different terms, provided the original work is properly cited, appropriate credit is given, any changes made indicated, and the use is non-commercial. See: http://creativecommons.org/licenses/by-nc/4.0/.

\section{ORCID iDs}

Abrar Arbaeen http://orcid.org/0000-0003-3880-8649

Nial J Wheate http://orcid.org/0000-0002-0505-1363
Rose Cairns http://orcid.org/0000-0002-8946-5079

\section{REFERENCES}

1 Polanczyk G, de Lima MS, Horta BL, et al. The worldwide prevalence of ADHD: a systematic review and metaregression analysis. $A m ~ J$ Psychiatry 2007;164:942-8.

2 Bachmann CJ, Wijlaars LP, Kalverdijk LJ, et al. Trends in ADHD medication use in children and adolescents in five Western countries, 2005-2012. Eur Neuropsychopharmacol 2017;27:484-93.

3 King SA, Casavant MJ, Spiller HA, et al. Pediatric ADHD medication exposures reported to US poison control centers. Pediatrics 2018;141:e20173872.

4 Spiller HA, Hays HL, Aleguas A. Overdose of drugs for attentiondeficit hyperactivity disorder: clinical presentation, mechanisms of toxicity, and management. CNS Drugs 2013;27:531-43.

5 Gummin DD, Mowry JB, Beuhler MC, et al. 2019 annual report of the American association of poison control centers' national poison data system (NPDS): 37th annual report. Clin Toxicol 2020;58:1360-541.

6 The social and economic costs of ADHD in Australia. Deloitte, 2019. Available: https://www2.deloitte.com/content/dam/Deloitte/au/ Documents/Economics/deloitte-au-economics-social-costs-adhdaustralia-270819.pdf

7 Pharmaceutical Benefits Scheme. Attention deficit hyperactivity disorder: utilisation analysis, 2018.

8 Klein-Schwartz W. Pediatric methylphenidate exposures: 7-year experience of poison centers in the United States. Clin Pediatr 2003;42:159-64.

9 Klein-Schwartz W. Abuse and toxicity of methylphenidate. Curr Opin Pediatr 2002;14:219-23.

10 Cairns R, Karanges EA, Wong A, et al. Trends in self-poisoning and psychotropic drug use in people aged 5-19 years: a populationbased retrospective cohort study in Australia. BMJ Open 2019;9:026001.

11 Brett J, Karanges EA, Daniels B, et al. Psychotropic medication use in Australia, 2007 to 2015: changes in annual incidence, prevalence and treatment exposure. Aust N Z J Psychiatry 2017;51:990-9.

12 Cairns R, Daniels B, Wood DA, et al. ADHD medication overdose and misuse: the NSW poisons information centre experience, 2004-2014. Med J Aust 2016;204:154-54.

13 Mellish L, Karanges EA, Litchfield MJ, et al. The Australian pharmaceutical benefits scheme data collection: a practical guide for researchers. BMC Res Notes 2015;8:1-13.

14 Barczyk ZA, Rucklidge JJ, Eggleston M, et al. Psychotropic medication prescription rates and trends for new Zealand children and adolescents 2008-2016. J Child Adolesc Psychopharmacol 2020;30:87-96.

15 The R project for statistical computing. Available: https://www.rproject.org/

16 ARIA Lookup Tool. Psycho-Oncology co-operative Research Group (the University of Sydney), 2018. Available: https://www.pocog. org. au/content.aspx?page=ariatool

17 Methylphenidate hydrochloride, Tablets, $18 \mathrm{mg}, 27 \mathrm{mg}, 36 \mathrm{mg}$, and 54 mg,(extended release) Concerta. PBS, 2012. Available: https:// www.pbs.gov.au/info/industry/listing/elements/pbac-meetings/psd/ 2012-07/methylphenidate-hydrochloride

18 Sonuga-Barke EJS, Brandeis D, Cortese S, et al. Nonpharmacological interventions for ADHD: systematic review and meta-analyses of randomized controlled trials of dietary and psychological treatments. Am J Psychiatry 2013;170:275-89.

19 Raman SR, Man KKC, Bahmanyar S, et al. Trends in attention-deficit hyperactivity disorder medication use: a retrospective observational study using population-based databases. Lancet Psychiatry 2018;5:824-35.

20 Prosser B, Reid R. Changes in use of psychostimulant medication for ADHD in South Australia (1990-2006). Aust N Z J Psychiatry 2009;43:340-7.

21 Calver J, Preen D, Bulsara M, et al. Stimulant prescribing for the treatment of ADHD in Western Australia: socioeconomic and remoteness differences. Med J Aust 2007;186:124-7.

22 McLachlan R, Gllfillan G, Gordon J. Deep and persistent disadvantage in Australia. productivity Commission staff working paper. Canberra: Australian Government Productivity Commission, 2013: 246pp. 